\title{
Penerapan Model Pembelajaran Direct Learning untuk Meningkatkan Hasil Belajar Mata Pelajaran Food and Beverage pada Kompetensi Menerapkan Teknik Platting dan Garnish
}

\section{Komang Wiwik Supartini ${ }^{*}$}

${ }^{1}$ SMK Negeri 2 Singaraja, Singaraja, Indonesia

\section{A R T I C L E I N F O}

Article history:

Received 08 February 2021

Received in revised form 30 March 2021

Accepted 10 April 2021 Available online 11 May 2021

\section{Kata Kunci:}

Model Direct Learning,

Hasil belajar.

Keywords:

Direct Learning Model, Learning Outcomes.

\begin{abstract}
A B S T R A K
Berdasarkan hasil observasi kompetensi siswa menerapkan Teknik Platting dan Garnish masih rendah, sehingga perlu ditingkatkan dengan penggunaan model pembelajaran yang dapat memotivasi siswa untuk belajar. Penelitian ini bertujuan untuk menganalisis peningkatan hasil belajar mata pelajaran Food and Beverage pada kompetensi menerapkan Teknik Platting dan Garnish siswa kelas XI Perhotelan 4 setelah diterapkannya model pembelajaran Direct Learning. Penelitian ini adalah penelitian tindakan kelas. Subjek penelitian ini adalah siswa kelas XI yang berjumlah 40 siswa. Sedangkan yang menjadi objek penelitian ini adalah peningkatan hasil belajar Food and Beverage kompetensi Menerapkan Teknik Platting dan Garnish. Metode pengumpulan data menggunakan metode observasi. Sedangkan teknik analisis data menggunakan teknik analisis data statistik kuantitatif. Hasil penelitian ini menunjukkan bahwa terdapat peningkatan hasil belajar siswa yaitu 78,08 pada siklus 1 dan 83,38 pada siklus 2 atau dari $37,50 \%$ menjadi $92,50 \%$, hal ini menunjukkan peningkatan yang signifikan sebesar $55 \%$. Simpulan
\end{abstract} penelitian ini adalah penerapan model pembelajaran Direct Learning dapat meningkatkan hasil belajar mata pelajaran Food and Beverage pada kompetensi menerapkan teknik Platting dan Garnish. Implikasi dari penelitian ini adalah penerapan model pembelajaran Direct Learning melatih siswa untuk mandiri dan bertanggungjawab serta dapat mengembangkan pengetahuan prosedural (pengetahuan tentang bagaimana melakukan sesuatu) secara terstruktur dengan baik.

A B S T R A K

Based on the results of observations, the competence of students applying the Platting and Garnish Technique is still low, so it needs to be improved by using a learning model that can motivate students to learn. This study aims to analyze the improvement of learning outcomes in Food and Beverage subjects on the competence of applying Platting and Garnish Techniques for class XI Hospitality 4 students after the implementation of the Direct Learning learning model. This research is a classroom action research. The subjects of this study were 40 students of class XI. Meanwhile, the object of this research is the improvement of learning outcomes Food and Beverage competence in Applying Platting and Garnish Techniques. Methods of data collection using the method of observation. While the data analysis technique uses quantitative statistical data analysis techniques. The results of this study indicate that there is an increase in student learning outcomes, namely 78.08 in cycle 1 and 83.38 in cycle 2 or from $37.50 \%$ to $92.50 \%$, this shows a significant increase of $55 \%$. The conclusion of this study is that the application of the Direct Learning learning model can improve learning outcomes in Food and Beverage subjects on the competence of applying Platting and Garnish techniques. The implication of this research is the application of the Direct Learning learning model to train students to be independent and responsible and to develop well-structured procedural knowledge (knowledge of how to do something). 


\section{Pendahuluan}

Pendidikan adalah suatu proses dalam rangka mempengaruhi peserta didik supaya mampu menyesuaikan diri sebaik mungkin dengan lingkungannya, dan dengan demikian akan menimbulkan perubahan dalam dirinya yang memungkinkannya untuk berfungsi secara optimal dalam kehidupan masyarakat. Pada dasarnya pertumbuhan dan perkembangan peserta didik bergantung pada dua unsur yang saling mempengaruhi, yakni bakat yang dimiliki oleh peserta didik sejak lahir, dan lingkungan yang mempengaruhi hingga bakat itu tumbuh dan berkembang (Krissandi \& Rusmawan, 2015; Sugiyanto et al., 2015; Wahyudin, 2018). Salah satu bakat yang dapat dikembangkan adalah Teknik Platting dan Garnish.

Kompetensi menerapkan Teknik Platting dan Garnish adalah merupakan salah satu bagian dari kompetensi pada mata pelajaran Food and Beverage yang diajarkan pada siswa perhotelan dengan tujuan memberikan berbagai keterampilan didalam menyajikan suatu hidangan agar lebih menarik dan memiliki nilai jual tinggi dari hidangan yang disajikan (Astuti et al., 2016; Febriana, 2017; Sari et al., 2014). Proses pembelajarannya lebih banyak menekankan pada keterampilan cara menghias dan menghidangkan suatu makanan, sehingga siswa menjadi lebih terampil dalam melakukan Teknik Platting dan Garnish. Dengan ciri pembelajaran tersebut, banyak siswa yang mengalami kesulitan dalam mengikuti proses pembelajaran Food and Beverage khususnya pada kompetensi menerapkan Teknik Platting dan Garnish, terutama pada siswa yang sama sekali belum mengenal seni dalam menghias dan menyajiakan hidangan.

Berdasarkan hasil observasi terhadap proses pembelajaran pada kompetensi menerapkan Teknik Platting kelas XI Perhotelan 4 tahun pelajaran 2019/2020 pada semester sebelumnya, bahwa aktivitas yang mencakup aspek afektif/keaktifan dan kemampuan unjuk kerja/psikomator dari 40 orang siswa menunjukkan hasil yang kurang maksimal yakni antara 30\% - 35\% saja dan selebihnya siswa pasif dalam mengikuti proses pembelajaran, selain itu hasil belajar yang ditunjukkan melalui ketuntasan belajar pada kompetensi menerapkan Teknik Platting dan Garnish hanya mencapai 37,50\% siswa. Dengan hasil tersebut dapat disimpulkan bahwa hasil belajar siswa kelas XI perhotelan 4 semester genap SMK Negeri 2 Singaraja tahun pelajaran 2019/2020 pada kompetensi menerapkan Teknik Platting dan Garnish masih rendah, sehingga perlu ditingkatkan. Dalam upaya meningkatkan kualitas pembelajaran siswa dalam berbagai mata pelajaran khususnya Food and Beverage telah banyak dicobakan model-model pembelajaran, namun tidak untuk kopetensi menerapkan Teknik Platting dan Garnish. Di samping itu hasil-hasil penelitian tersebut jarang diimplementasikan dalam proses pembelajaran, padahal secara umum hasil penelitian tersebut menunjukkan bahwa model pembelajaran yang diteliti efektif dalam memperbaiki kualitas pembelajaran siswa khususnya dalam pembelajaran Food and Beverage di Sekolah.

Hasil wawancara dengan beberapa orang siswa yang mengikuti pembelajaran Food and Beverage pada kompetemsi Teknik Platting dan Garnish, menunjukan antusias mereka dalam mengikuti pembelajaran cukup tinggi, mengingat pentingnya pengusaan keterampilan bagi mereka. Sebab dengan keterampilan menghias dan menyajikan makanan secara menarik yang dimiliki oleh siswa memiliki arti penting dan manfaat bagi siswa tersebut. Akan tetapi kekurang mampuan guru dalam mendesain proses pembelajaran dengan baik di kelas menyebabkan materi diberikan kurang dapat dipahami siswa dengan baik sehingga siswa kurang aktif dalam mengikuti pembelajaran dan hasil belajarnya pun juga kurang maskimal. Teknik Platting dan Garnish menuntut adanya ketrampilan yang dilakukan secara tahap demi tahap dari seluruh rangkaian kegiatan yang ditampilkan. Selain itu juga guru dalam pemberian contoh atau mendemontrasikan keterampilan yang diajarkan masih kurang, sehingga menjadikan kurangnya pemahaman siswa terhadap Teknik Platting dan Garnish tersebut. Untuk itu seorang guru dituntut mampu mengembangkan berbagai macam model pembelajaran dengan bantuan media yang diterapkan pada pembelajaran praktik, sehingga proses pembelajaran dapat berlangsung dengan baik dan berkualitas. Salah satu model pembelajaran yang efektif adalah model direct instruction.

Direct Instruction adalah suatu model pembelajaran yang dapat membantu siswa mempelajari keterampilan dasar dan memperoleh informasi yang dapat diajarkan selangkah demi selangkah (Damanik \& Bukit, 2013; Falentina, 2017; Maarif et al., 2020). Model pembelajaran langsung dirancang secara khusus untuk mengembangkan belajar siswa tentang pengetahuan prosedural dan pengetahuan deklaratif yang terstruktur dengan baik dan dapat dipelajari selangkah demi selangkah. Landasan teoritik model pembelajaran langsung adalah teori belajar sosial, yang juga disebut belajar melalui observasi, atau disebut teori pemodelan tingkah laku (Safarilis, 2018; Safputri et al., 2016; Yanti, 2019).

Model pembelajaran Direct Instruction merupakan model pembelajaran yang baik untuk mengajarkan tentang aturan, prosedur, keterampilan dasar, khususnya siswa siswa yang masih muda belia, sehingga model pembelajaran langsung sangat sesuai diterapkan dalam mengajarkan teknik Platting dan Garnish (Rais \& Suswanto, 2017; Saputro, 2016; Wintarti, 2017). Model Direct Instruction terdiri dari lima tahap aktivitas yakni orientasi, presentasi, praktik yang terstruktur, praktik di bawah bimbingan, dan praktik mandiri yaitu: (1) yaitu orientasi, diawali dengan menentukan materi pembelajaran, meninjau 
pelajaran sebelumnya, menentukan tujuan pembelajaran dan menentukan prosedur; (2) yaitu presentasi, presentasi diawali dengan menjelaskan konsep atau keterampilan baru, menyajikan represntasi visual atas tugas yang diberikan dan memastikan pemahaman; (3) yaitu praktik yang terstruktur, dimulai dengan menenuntun kelompok siswa dengan contoh praktik beberapa langkah, lalu siswa merespon dengan pertanyaan dan diakhiri dengan memberikan koreksi terhadap kesalahan lalu memperkuat praktik yang benar; (4) yaitu praktik di bawah bimbingan guru, dimana siswa berpraktik secara semiindependen, dilanjutkan dengan menggilir siswa untuk melakukan praktik dan mengamati praktik, lalu guru memberikan tanggapan balik berupa petunjuk; (5) yaitu praktik mandiri, dalam tahapan ini siswa melakukan praktik secara mandiri di kelas atau di rumah, guru menunda respons balik dan memberikannya di akhir rangkaian praktik dan praktik mandiri dilakukan beberapa kali dalam waktu periode yang lama (Hastari et al., 2020; Jamilah et al., 2017; Royani et al., 2018).

Kelebihan model pembelajaran Direct Learning dapat melatih siswa untuk mandiri dan bertanggungjawab serta dapat mengembangkan pengetahuan prosedural (pengetahuan tentang bagaimana melakukan sesuatu) secara terstruktur dengan baik (Haryanti et al., 2018; Kusumawati, 2016; Usman, 2014). Karakteristik model pembelajaran Direct Instruction, yaitu: (1) adanya tujuan pembelajaran dan pengaruh model pada siswa termasuk prosedur penilaian hasil belajar; (2) adanya sintaks atau pola keseluruhan dan alur kegiatan pembelajaran; (3) sistem pengelolaan dan lingkungan belajar model yang diperlukan agar kegiatan pembelajaran tertentu dapat berlangsung dengan berhasil (Damanik \& Bukit, 2013; Falentina, 2017; Maarif et al., 2020).

Tujuan penerapan model Pembelajaran Direct Instruction adalah agar siswa mudah memahami serta dapat mempraktikan segala teknik Platting dan Garnish yang diajarkan dengan baik dan benar (Immanuel, 2017; Kusumawati, 2016; Wahyuningsih et al., 2013). Setidaknya para siswa mampu melihat serta mengkoreksi Teknik Platting dan Garnish yang dilakukan dengan benar. Dalam mengajarkan teknik Platting dan Garnish hendaknya guru berfikir bagaimana penyampaian materi tersebut dapat dipahami secara baik oleh siswa, sehingga pembelajaran teknik tersebut dapat berjalan secara efektif dan efisien. Secara tidak langsung kualitas yang dimunculkan dalam kompetensi menerapkan Teknik Platting dan Garnish pada mata pelajaran Food and Beverage akan mempengaruhi hasil belajar siswa terhadap mata pelajaran tersebut secara keseluruhan.

Penerapan Model Pembelajaran Direct Learning didukung dengan penelitian sebelemnya yang rlevan dngan penelitian ini, seperti: (1) penelitian yang dilakukan oleh (Haryanti et al., 2018), yang mendapatkan hasil bahwa penggunaan model pembelajaran Direct Instruction berbantuan media bagan garis waktu dapat meningkatkan hasil belajar siswa; (2) penelitian yang dilakukan oleh (Jamilah et al., 2017), yang mendapatkan hasil bahwa model penemuan terbimbing dan pembelajaran langsung terbukti dapat meningkatkan kemampuan pembuktian matematis siswa; (3) penelitian yang dilakukan oleh (Usman, 2014), yang mendapatkan hasil bahwa model Direct Instruction dapat meningkatkan kemampuan siswa menyusun laporan keuangan.

Tujuan penelitian ini adalah untuk menganalisis hasil belajar mata pelajaran Food and Beverage pada kompetensi menerapkan Teknik Platting dan Garnish siswa kelas XI Perhotelan 4 semester genap SMK Negeri 2 Singaraja tahun pelajaran 2019/2020.

\section{Metode}

Penelitian ini dirancang sebagai penelitian tindakan kelas (PTK) yang bertujuan untuk memecahkan permasalahan yang nyata yang terjadi di kelas dan meningkatkan kegiatan nyata guru dalam pengembangan profesinya. Tujuan utama penelitian ini adalah untuk meningkatkan hasil belajar dan memecahkan permasalahan yang dihadapi secara nyata oleh siswa dalam proses pembelajaran. Penelitian yang dilakukan termasuk penelitian tindakan yang dilakukan dalam 2 siklus. Dalam melaksanakan penelitian, rancangan merupakan hal yang sangat penting untuk disampaikan. Tanpa rancangan, bisa saja alur penelitian akan ngawur dalam pelaksanaannya.

Pelaksanaan penelitian direncanakan berlangsung dari bulan Desember sampai bulan Maret 2020 pada SMK Negeri 2 Singaraja. Penelitian ini dilaksanakan pada semester genap tahun pelajaran 2019/2020. Subjek dalam penelitian ini adalah semua siswa kelas XI Perhotelan 4 SMK Negeri 2 Singaraja yang berjumlah 40 siswa. Sedangkan yang menjadi objek penelitian ini adalah peningkatan hasil belajar Food and Beverage kompetensi Menerapkan Teknik Platting dan Garnish kelas XI P4 semester genap SMK Negeri 2 Singaraja setelah menggunakan model pembelajaran Direct Instruction dalam proses pembelajaran.

Metode pengumpulan data pada penelitian ini menggunakan metode observasi. Data hasil belajar diperoleh dari hasil evaluasi akhir pada setiap siklus berupa nilai akhir. Nilai hasil belajar siswa langsung 
diperoleh oleh guru berupa nilai teori dari post test pada masing-masing siklus dan nilai praktek berupa unjuk kerja yang diperoleh dari lembar observasi.

Teknik analisis data yang digunakan pada penelitian ini adalah teknik analisis data statistik kuantitatif. Teknik ini digubakan untuk menganalisis hasil belajar mata pelajaran Food and Beverage pada kompetensi menerapkan Teknik Platting Dan Garnish siswa kelas XI Perhotelan 4 semester genap SMK Negeri 2 Singaraja tahun pelajaran 2019/2020.

\section{Hasil dan Pembahasan}

Penelitan yang telah dilaksanakan pada siklus 1 dan siklus 2 menunjukkan adanya peningkatan dalam penggunaan model pembelajaran Direct Instruction (Pembelajaran Langsung) terhadap hasil belajar mata pelajaran Food and Beverage Kompetensi Menerapkan Teknik Platting dan Garnish semester genap kelas XI P 4 SMK Negeri 2 Singaraja tahun pelajaran 2019/2020.

Pada siklus 1 nilai rata-rata siswa adalah 78,08 dan ada 25 orang siswa dari 40 orang siswa yang belum tuntas sehingga belum sesuai dengan apa yang diharapkan. Dari hasil siklus 1 kemudian diadakan perbaikan pada siklus 2 , diperoleh nilai rata-rata 83,38 . Hal ini menunjukkan ada peningkatan dari siklus 1 ke siklus 2 sebesar 55\%. Dengan adanya model pembelajaran Direct Instruction (Pembelajaran Langsung) dalam proses belajar mengajar baik yang dilaksanakan oleh guru dan siswa diharapkan dapat meningkatkan hasil belajar yang lebih baik yang dapat membawa perubahan positif pada perbaikan proses pembelajaran.

Dari hasil penelitian dan hasil belajar siswa, KKM membuktikan bahwa pembelajaran model Direct Instruction (Pembelajaran Langsung) dapat meningkatkan hasil belajar siswa pada mata pelajaran Food and Beverage kompetensi Menerapkan Teknik Platting dan Garnish.

Sedangkan hasil respon siswa terhadap pembelajaran model Direct Instruction (Pembelajaran Langsung) pada siklus 1 diperoleh rata-rata respon siswa sebesar 31,73 dengan katagori sedang dengan prosentase jumlah siswa yang memiliki respon sangat tinggi sebesar 2,5 \% (1 orang), katagori tinggi 22,50 $\%$ (9 orang), katagori sedang 67,50 \%(27 orang), dan katagori rendah 7,50 \% (3 orang). Sedangkan hasil respon siswa pada siklus 2 rata-rata respon siswa sebesar 36,25 dengan katagori tinggi dengan prosentase jumlah siswa yang memiliki respon sangat tinggi sebesar $20 \%$ ( 8 orang), katagori tinggi 32,5 $\%$ (13 orang) , katagori sedang 47,5 \% (19 orang). Dengan demikian dapat disimpulkan bahwa terjadi peningkatan yang signifikan terhadap respon belajar siswa pada mata pelajaran Food and Beverage Kompetensi Menerapkan Teknik Platting dan Garnish, hal ini dimungkinkan oleh karena siswa merasa bahwa model ini adalah model baru yang dirasakan dalam pembelajaran. Pembelajaran Direct Instruction merupakan model pembelajaran yang baik untuk mengajarkan tentang aturan, prosedur, keterampilan dasar, khususnya siswa siswa yang masih muda belia, sehingga model pembelajaran langsung sangat sesuai diterapkan dalam mengajarkan teknik Platting dan Garnish (Rais \& Suswanto, 2017; Saputro, 2016; Wintarti, 2017).

Model Direct Instruction terdiri dari lima tahap aktivitas yakni orientasi, presentasi, praktik yang terstruktur, praktik di bawah bimbingan, dan praktik mandiri yaitu: (1) yaitu orientasi, diawali dengan menentukan materi pembelajaran, meninjau pelajaran sebelumnya, menentukan tujuan pembelajaran dan menentukan prosedur; (2) yaitu presentasi, presentasi diawali dengan menjelaskan konsep atau keterampilan baru, menyajikan represntasi visual atas tugas yang diberikan dan memastikan pemahaman; (3) yaitu praktik yang terstruktur, dimulai dengan menenuntun kelompok siswa dengan contoh praktik beberapa langkah, lalu siswa merespon dengan pertanyaan dan diakhiri dengan memberikan koreksi terhadap kesalahan lalu memperkuat praktik yang benar; (4) yaitu praktik di bawah bimbingan guru, dimana siswa berpraktik secara semi-independen, dilanjutkan dengan menggilir siswa untuk melakukan praktik dan mengamati praktik, lalu guru memberikan tanggapan balik berupa petunjuk; (5) yaitu praktik mandiri, dalam tahapan ini siswa melakukan praktik secara mandiri di kelas atau di rumah, guru menunda respons balik dan memberikannya di akhir rangkaian praktik dan praktik mandiri dilakukan beberapa kali dalam waktu periode yang lama (Hastari et al., 2020; Jamilah et al., 2017; Royani et al., 2018).

Kelebihan model pembelajaran Direct Learning dapat melatih siswa untuk mandiri dan bertanggungjawab serta dapat mengembangkan pengetahuan prosedural (pengetahuan tentang bagaimana melakukan sesuatu) secara terstruktur dengan baik (Haryanti et al., 2018; Kusumawati, 2016; Usman, 2014). Karakteristik model pembeelajaran Direct Instruction, yaitu: (1) adanya tujuan pembelajaran dan pengaruh model pada siswa termasuk prosedur penilaian hasil belajar; (2) adanya sintaks atau pola keseluruhan dan alur kegiatan pembelajaran; (3) sistem pengelolaan dan lingkungan belajar model yang diperlukan agar kegiatan pembelajaran tertentu dapat berlangsung dengan berhasil (Damanik \& Bukit, 2013; Falentina, 2017; Maarif et al., 2020). 
Tujuan penerapan model Pembelajaran Direct Instruction adalah agar siswa mudah memahami serta dapat mempraktikan segala teknik Platting dan Garnish yang diajarkan dengan baik dan benar (Immanuel, 2017; Kusumawati, 2016; Wahyuningsih et al., 2013). Setidaknya para siswa mampu melihat serta mengkoreksi Teknik Platting dan Garnish yang dilakukan dengan benar. Dalam mengajarkan teknik Platting dan Garnish hendaknya guru berfikir bagaimana penyampaian materi tersebut dapat dipahami secara baik oleh siswa, sehingga pembelajaran teknik tersebut dapat berjalan secara efektif dan efisien. Secara tidak langsung kualitas yang dimunculkan dalam kompetensi menerapkan Teknik Platting dan Garnish pada mata pelajaran Food and Beverage akan mempengaruhi hasil belajar siswa terhadap mata pelajaran tersebut secara keseluruhan.

Penerapan Model Pembelajaran Direct Learning didukung dengan penelitian sebelemnya yang rlevan dngan penelitian ini, seperti: (1) penelitian yang dilakukan oleh (Haryanti et al., 2018), yang mendapatkan hasil bahwa penggunaan model pembelajaran Direct Instruction berbantuan media bagan garis waktu dapat meningkatkan hasil belajar siswa; (2) penelitian yang dilakukan oleh (Jamilah et al., 2017), yang mendapatkan hasil bahwa model penemuan terbimbing dan pembelajaran langsung terbukti dapat meningkatkan kemampuan pembuktian matematis siswa; (3) penelitian yang dilakukan oleh (Usman, 2014), yang mendapatkan hasil bahwa model Direct Instruction dapat meningkatkan kemampuan siswa menyusun laporan keuangan.

Implikasi dari pelaksanaan penelitian tindakan kelas ini adalah penerapan model pembelajaran Direct Learning melatih siswa untuk mandiri dan bertanggungjawab serta dapat mengembangkan pengetahuan prosedural (pengetahuan tentang bagaimana melakukan sesuatu) secara terstruktur dengan baik.

\section{Simpulan}

Berdasarkan hasil Penelitian Tindakan Kelas dapat disimpulkan bahwa penerapan model pembelajaran Direct Learning dapat meningkatkan hasil belajar mata pelajaran Food And Beverage pada kompetensi menerapkan teknik Platting dan Garnish siswa kelas XI Perhotelan 4 semester genap SMK Negeri 2 Singaraja tahun pelajaran 2019/2020. Implikasi dari penelitian ini adalah penerapan model pembelajaran Direct Learning melatih siswa untuk mandiri dan bertanggungjawab serta dapat mengembangkan pengetahuan prosedural (pengetahuan tentang bagaimana melakukan sesuatu) secara terstruktur dengan baik.

\section{Daftar Rujukan}

Astuti, Y., Sonhadji, A., \& Nyoto, A. (2016). Pengembangan Buku Ajar Mata Pelajaran Tata Hidang Paket Keahlian Jasa Boga Sekolah Menengah Kejuruan. Jurnal Pendidikan: Teori, Penelitian, Dan Pengembangan, 1(1). https://doi.org/10.17977/jp.v1i1.6603

Damanik, D. P., \& Bukit, N. (2013). Analyze Critical Thinking Skills And Scientific Attitude In Physics Learning Used Inquiry Training And Direct Instruction Learning Model. Jurnal Pendidikan Fisika, 2(1), 16-24. https://doi.org/10.22611/jpf.v2i1.4333

Falentina, U. (2017). Memanfaatkan Metode Kerja Kelompok dalam Model Direct Instruction Untuk Mengoptimalkan Peningkatan Prestasi Belajar Matematika Siswa Kelas 8 Semester I Tahun Pelajaran 2015/2016 DI SMPN 8 Bintan. Jurnal Ilmiah Pendidikan Matematika, 5(2), 131-137. https://doi.org/10.25273/jipm.v5i2.1176

Febriana, R. (2017). Efektivitas Model Pembelajaran Berbasis Kompetensi Dengan Pendekatan Dunia Kerja Pada Program D3 Tata Boga. Cakrawala Pendidikan: Jurnal Ilmiah Pendidikan, 36(1), 148155. https://doi.org/10.21831/cp.v36i1.8891

Haryanti, Y. D., Febriyanto, B., \& Nuraisyah, I. F. (2018). Upaya Meningkatkan Hasil Belajar Siswa Melalui Model Direct Instruction Berbantuan Media Bagan Garis Waktu. Jurnal Cakrawala Pendas, 4(2), 23-41. https://doi.org/10.31949/jcp.v4i2.1074

Hastari, R. C., Zuhroh, Y. E., Purwanto, P., \& Susiana, A. (2020). Kesalahan Mahasiswa dalam Menyelesaikan Soal Matematika pada Penerapan Model Pembelajaran Langsung (Direct Instruction). JURNAL Tadris Matematika, 3(1), 21-30. https: //doi.org/10.21274/jtm.2020.3.1.21-30

Immanuel, F. (2017). Upaya Peningkatan Hasil Belajar Siswa Melalui Model Pembelajaran Langsung Mata Pelajaran Matematika Kelas VIII-4 SMPN 1 Namorambe. Jurnal Handayani: Jurnal Kajian Pendidikan Pra Sekolah Dan Pendidikan Dasar, 6(2), 118-123. 
Jamilah, J., Hartono, H., \& Susiaty, U. D. (2017). Komparasi Model Penemuan Terbimbing Dan Pembelajaran Langsung Terhadap Kemampuan Pembuktian Matematis. Jurnal Aksioma, 6(2), 218-224. https://doi.org/10.24127/ajpm.v6i2.962

Krissandi, A. D. S., \& Rusmawan, R. (2015). Kendala Guru Sekolah Dasar Dalam Implementasi Kurikulum 2013. Jurnal Cakrawala Pendidikan, 3(3), 457-467. https://doi.org/10.21831/cp.v3i3.7409

Kusumawati, N. (2016). Pengembangan Media Pembelajaran Ipa Dengan Animasi Macromedia Flash Berbasis Model Pengajaran Langsung (Direct Instruction) Di Sekolah Dasar. Premiere Educandum, 5(2). https://doi.org/10.25273/pe.v5i02.289

Maarif, M., Fauziah, M., \& Fauzi, R. (2020). Effectiveness Of Direct Instruction For Learning Models Improving Batik Skills In Basic School Students In Sanggar Batik Cikadu. Jurnal Pajar (Pendidikan Dan Pengajaran), 4(1), 151-158. https://doi.org/10.33578/pjr.v4i1.7894

Rais, A. A., \& Suswanto, H. (2017). Perbandingan Implementasi Model Problem Based Learning Dan Direct Instruction Dalam Meningkatkan Motivasi Dan Hasil Belajar Siswa Pada Mata Pelajaran Jaringan Dasar Kelas X. Jurnal Pendidikan: Teori, Penelitian, Dan Pengembangan, 2(8). https://doi.org/10.17977/jptpp.v2i8.9787

Royani, I., Mirawati, B., \& Jannah, H. (2018). Pengaruh Model Pembelajaran Langsung Berbasis Praktikum Terhadap Keterampilan Proses Sains dan Kemampuan Berpikir Kritis Siswa. Prisma Sains: Jurnal Pengkajian Ilmu Dan Pembelajaran Matematika Dan Ipa Ikip Mataram, 6(2), 46-55. https://doi.org/10.33394/j-ps.v6i2.966

Safarilis, S. (2018). Penggunaan Model Pembelajaran Langsung Untuk Meningkatkan Hasil Belajar PKN Siswa Kelas VI SD Negeri 008 Pulau Rumput. Jurnal Pajar (Pendidikan Dan Pengajaran), 2(2), 282287. https://doi.org/10.33578/pjr.v2i2.5077

Safputri, E. I., Zainuddin, Z., \& Mastuang, M. (2016). Pengembangan Perangkat Pembelajaran Fisika Pada Materi Ajar Usaha dan Energi Dengan Metode Problem Posing Dalam Setting Model Pengajaran Langsung Pada Siswa Kelas XI SMAN 4 Banjarmasin. Berkala Ilmiah Pendidikan Fisika, 4(2), 9198. https://doi.org/10.20527/bipf.v4i2.1032

Saputro, B. (2016). Manajemen Pembelajaran Direct Instruction Dalam Praktikum IPA Sebagai Kunci Keberhasilan Guru IPA Di Laboratorium. Satya Widya, 32(1), 1-10. https://doi.org/10.24246/j.sw.2016.v32.i1.p1-10

Sari, K., Setiyowati, E., \& Indrawati, S. A. (2014). Pengaruh Penerapan Metode Cooperative Learning Model Jigsaw Pada Layanan Bimbingan Klasikal Terhadap Pemahamanself Regulated Learning (Studi Eksperimen Pada Siswa Kelas XI Tata Boga 3 SMK Negeri 30 Jakarta). Insight: Jurnal Bimbingan Dan Konseling, 3(2), 63-69. https://doi.org/10.21009/INSIGHT.032.11

Sugiyanto, S., Kartowagiran, B., \& Jailani, J. (2015). Pengembangan Model Evaluasi Proses Pembelajaran Matematika Di SMP Berdasarkan Kurikulum 2013. Jurnal Penelitian Dan Evaluasi Pendidikan, 19(1), 82-95. https://doi.org/10.21831/pep.v19i1.4558

Usman, U. (2014). Penerapan Model Direct Instruction untuk Meningkatkan Kemampuan Siswa Menyusun Laporan Keuangan di SMK Negeri 1 Tarakan. Jurnal Pendidikan Humaniora, 1(3), 320-326. https://doi.org/10.17977/jph.v1i3.4141

Wahyudin, W. (2018). Optimalisasi Peran Kepala Sekolah dalam Implementasi Kurikulum 2013. Jurnal Kependidikan, 6(2), 249-265. https://doi.org/10.24090/jk.v6i2.1932

Wahyuningsih, T., Rezeki, S., \& Zetriuslita. (2013). Perbandingan Hasil Belajar Matematika Siswa Melalui Penerapan Model Pembelajaran Langsung dengan Pembelajaran Kooperatif. Jurnal Matematika, 3(1), 52-63. https://doi.org/10.24843/JMAT.2013.v03.i02.p35

Wintarti, W. (2017). Upaya Meningkatkan Prestasi Belajar IPS Melalui Model Pembelajaran DI (Direct Instruction) Dengan Media Visual Berbantuan Komputer. Premiere Educandum, 7(1), 28-38. https://doi.org/10.25273/pe.v7i01.1161

Yanti, W. (2019). Penggunaan Model Pembelajaran Langsung (Direct Instruction) Untuk Meningkatkan Hasil Belajar Biologi Siswa Kelas X IPA 1 SMA Negeri 15 Kota Takengon Tahun Pelajaran 20182019. Biotik: Jurnal Ilmiah Biologi Teknologi Dan Kependidikan, 7(2), 115-120. https://doi.org/10.22373/biotik.v7i2.5652 